\title{
Microvascular Thrombosis and Ischaemic Limb Losses in Critically III Patients
}

Theodore E. Warkentin $1,2,3,4,5$

${ }^{1}$ Department of Pathology and Molecular Medicine, Michael G. DeGroote School of Medicine, McMaster University, Hamilton, Ontario, Canada

2 Transfusion Medicine, Hamilton Regional Laboratory Medicine Program, Hamilton, Ontario, Canada

${ }^{3}$ Service of Clinical Hematology, Hamilton Health Sciences, Hamilton General Hospital, Hamilton, Ontario, Canada

${ }^{4}$ McMaster Centre for Transfusion Research, McMaster University, Hamilton, Ontario, Canada

${ }^{5}$ Department of Medicine, Michael G. DeGroote School of Medicine, McMaster University, Hamilton, Ontario, Canada

Address for correspondence Theodore E. Warkentin, MD, Hamilton Regional Laboratory Medicine Program, Hamilton General Hospital, Room 1-270B, 237 Barton St. E., Hamilton, Ontario L8L 2X2, Canada (e-mail: twarken@mcmaster.ca).

Hämostaseologie 2019;39:6-19.

\author{
Abstract \\ Keywords \\ - acute ischaemic \\ hepatitis ('shock \\ liver') \\ - antithrombin \\ - disseminated \\ intravascular \\ coagulation \\ - protein C \\ - symmetrical \\ peripheral gangrene \\ - vasopressors
}

Zusammenfassung
Relatively little scientific attention has been given to the small subset of critically ill patients with circulatory shock who develop ischaemic limb losses (symmetrical peripheral gangrene [SPG]). The clinical picture consists of acral (distal extremity) tissue necrosis involving lower limbs in a largely symmetrical fashion and with detectable arterial pulses; in one-third of patients the upper extremities are also affected (potential for four-limb amputations). The laboratory picture includes thrombocytopenia, coagulopathy, and normoblastemia (circulating nucleated red blood cells). The explanation for limb losses is microvascular thrombosis caused by disseminated intravascular coagulation usually secondary to cardiogenic or septic shock. A common myth is that vasopressors cause the ischaemic limb injury. However, the more likely explanation is failure of the natural anticoagulant systems (protein $C$ and antithrombin) to downregulate thrombin generation in the microvasculature. This is because more than $90 \%$ of patients with SPG have preceding 'shock liver', which occurs 2 to 5 days (median, 3 days) prior to ischaemic limb injury, with impaired hepatic production of protein $\mathrm{C}$ and antithrombin.

Die kleine Gruppe kritisch kranker Patienten mit Herz-Kreislauf-Schock und ischämisch bedingter Extremitäten-Gangrän hat bislang relativ wenig wissenschaftliche Aufmerksamkeit erfahren. Das klinische Bild besteht aus ischämischen Gewebsnekrosen der Akren trotz nachweisbarem arteriellen Puls. Die Nekrosen treten typischerweise received

September 20, 2018

accepted after revision

November 2, 2018 (c) 2019 Georg Thieme Verlag KG Stuttgart · New York
DOI https://doi.org/

10.1055/s-0038-1676823.

ISSN 0720-9355. 


\author{
Schlüsselwörter \\ - akute ischämisce \\ Hepatitis \\ ('Schockleber') \\ - Antithrombin \\ - Disseminierte \\ intravaskuläre \\ Koagulation \\ - Protein C \\ - Symmetrisches \\ peripheres Gangrän \\ - Vasopressoren
}

symmetrisch und vor allem an den unteren Extremitäten auf. Bei ca. einem Drittel der Patienten sind auch die Finger/Hände betroffen (Risiko der Amputation aller vier Extremitäten). Die Laborergebnisse zeigen die Konstellation von Thrombozytopenie, Koagulopathie und zirkulierenden Normoblasten (kernhaltigen Erythrozyten). Der Extremitätenverlust wird verursacht durch mikrovaskuläre Thrombosen bei disseminierter Koagulopathie infolge eines kardiogenen oder septischen Schocks. Ein weit verbreiteter Irrglaube ist, dass Vasopressoren eine Ischämie der Akren/Extremitäten verursachen. Die viel wahrscheinlichere Erklärung dürfte sein, dass ein Versagen der natürlichen antikoagulatorischen Systeme (Protein C, Antithrombin) aufgrund einer Leberschädigung dazu führt, dass die Thrombinbildung in der Mikrozirkulation nicht ausreichend gehemmt wird. Mehr als $90 \%$ der Patienten mit symmetrischer Extremitäten-Gangrän haben eine 'Schockleber', die 2-5 Tage (im Median 3 Tage) vor Entstehung der Extremitäten-Gangrän auftritt und zu mit eingeschränkter Synthese von Protein C und Antithrombin führt.

\section{Introduction}

Ischaemic limb losses occur in a minority of critically ill patients with haemodynamic shock complicated by disseminated intravascular coagulation (DIC). ${ }^{1}$ Besides circulatory failure ('shock'), these patients invariably have multiorgan failure (e.g., respiratory, renal, hepatic, and haematologic) and usually die. However, when treatment is successful in saving the life of the patient, there can be permanent sequelae of acral (distal extremity) tissue losses, ranging from tips of fingers and toes to bilateral below-knee and even forearm amputations. Due to the often strikingly symmetrical nature of the limb injuries, the term 'symmetrical peripheral gangrene', or SPG, was given 80 years ago by Perry and Davie. ${ }^{2}$

The pathogenesis of SPG is microvascular thrombosis related to DIC, resulting in irreversible tissue necrosis; the distal extremities can be lost even as the other organs (lungs, liver, and kidneys) recover. Occurrence of microvascular thrombosis, rather than large-artery thrombosis, explains why arterial pulses are usually palpable (or identifiable by Doppler probes) in patients with SPG. The feet are almost always affected; in about one-third of patients, the hands are also involved. The term 'purpura fulminans' is used when additional nonacral skin necrosis is prominent. ${ }^{1}$

\section{History}

The first reports of SPG featured patients with cardiogenic shock, typically after myocardial infarction. ${ }^{2,3}$ Subsequently, the spectrum of disorders associated with SPG was expanded to include septic shock (discussed subsequently). Of note, SPG entered the medical literature prior to the modern concept of DIC.

\section{Symmetrical Peripheral Gangrene Association with Intravascular Coagulation}

The recognition that systemic infection can trigger DIC and tissue necrosis (particularly, adrenal haemorrhagic necrosis and renal cortical necrosis) began in the $1960 \mathrm{~s} .{ }^{4,5}$ Corrigan et al found that systemic infection commonly triggered activation of haemostasis. ${ }^{6}$ Two reports published in 1970 argued for DIC as the explanation for SPG complicating infection: Stossel and Levy ${ }^{7}$ reported a patient who developed SPG during postsplenectomy sepsis, with DIC diagnosed by thrombocytopenia, elevated serum fibrin-split products, and fibrin microthrombi (skin biopsy), whereas Chaudhuri and McKenzie ${ }^{8}$ described a child with infection-associated digital necrosis with underlying DIC indicated by severe thrombocytopenia.

A key paper by Molos and Hall, published in 1985 in Archives of Dermatology, ${ }^{9}$ identified DIC as 'the most common underlying condition' associated with SPG, occurring in at least $90 \%$ of patients. These authors reported three new cases of SPG (all with sepsis), and they reviewed 68 previously reported patients in the English language literature. Molos and Hall found infection to be the most common disorder associated with SPG, with cardiac disorders occurring in most of the remaining cases.

\section{Symmetrical Peripheral Gangrene Association with Shock}

A further important contribution to the SPG literature was made in 2000 by Knight and coworkers. ${ }^{10}$ These workers reported two new cases, but also reviewed the literature, confirming the frequent association between SPG and DIC. But they also emphasized the association with shock, stating that SPG occurs in 'patients who are septic and have DIC and in nonseptic patients who have cardiogenic or hypovolemic shock'. The two most important factors identified by Knight et al were 'sepsis and/or a low-flow state (i.e., cardiogenic or hypovolemic shock)' and 'the presence of DIC'.

Knight et al were perplexed why only a small minority of patients with shock and DIC develop SPG, commenting that a 'unified concept that explains all cases is lacking. ${ }^{10}$ Interestingly, the authors speculated that 'immunologic or molecular events not yet identified' could be responsible for SPG. Indeed, these authors were prescient, as an 'immunologic' mechanism rarely responsible for SPG has subsequently been identified (immune heparin-induced thrombocytopenia, 
HIT). Further, 'molecular events' are now recognized, namely acquired depletion of two crucial natural anticoagulants, antithrombin (AT) and protein C (PC).

\section{Histopathology}

SPG is associated with noninflammatory fibrinous deposits within small vessels (fibrin microthrombi). ${ }^{11}$ The microthrombi occur in separate sites, namely the distal extremities (in a strikingly symmetrical appearance), with usual contemporaneous onset. During the 1970s, the nexus between systemic hypercoagulability (DIC) and SPG emerged, when histopathology studies by Robboy and colleagues ${ }^{12,13}$ found thrombosis in capillaries and venules of the integument ('small vessels of the skin'), in patients who had developed one or more of 'purpura, purpura fulminans, gangrene, acrocyanosis, and haemorrhagic bullae'.

\section{Frequency of Symmetrical Peripheral Gangrene in Critically III Patients}

Despite the enormous literature on sepsis, it is hard to find data regarding the frequency of SPG in this patient population. One problem is that patients with evolving SPG often die, and so otherwise inevitable progression to limb amputations is not documented. An estimated frequency of approximately $2 \%$ is suggested by a large study that evaluated recombinant activated PC (rAPC) for the treatment of septicaemia: 'purpura fulminans' (proxy for SPG) was noted in 77/ 4,096 (1.9\%) of enrolled adult patients. ${ }^{14}$

A somewhat higher frequency was suggested by Johansen and Hansen, ${ }^{15}$ who identified 10 patients with SPG in association with pneumococcal septicemia (Streptococcus pneumoniae) over 15 years; as 165 patients were diagnosed with pneumococcal sepsis during this period, the frequency of SPG was estimated at $6.1 \%(10 / 165)$.

In a retrospective study ${ }^{16}$ of 63 critically ill patients with catecholamine-resistant vasodilatory shock, 19 (30\%) developed 'ischaemic skin lesions' (involving distal limbs in 17/19 patients); the mortality rate was $84 \%$ in this patient subgroup. Independent risk factors for developing ischaemic limb injury included septic shock and preexisting arterial disease.

A randomized trial ${ }^{17}$ of vasopressin versus norepinephrine infusion for patients with septic shock reported a frequency of 2.0 versus $0.5 \%$, respectively $(p=0.11)$, for the secondary end point of 'digital ischaemia'.

\section{Vasopressors and Symmetrical Peripheral Gangrene}

Interestingly, the aforementioned studies ${ }^{14-17}$ that provide some insight into the SPG frequency in critical illness do not provide strong evidence for an independent role for vasopressor therapy in explaining this complication. For example, in the rAPC trial, ${ }^{14}$ the frequency of vasopressor use at baseline was similar in the adult patients who developed purpura fulminans versus those who did not (77 vs. $70 \%$; $p=0.21$ by Fisher's exact test).

Johansen and Hansen, in their study of pneumococcal septicemia-associated SPG, ${ }^{15}$ while noting a high frequency of DIC (at least $80 \%$ ), observed that only $2 / 10$ (20\%) patients had received vasopressor therapy prior to onset of limb ischaemia. The authors concluded: 'the pathogenesis of peripheral cutaneous gangrene associated with pneumococcal sepsis is probably not iatrogenic'.

Dünser and colleagues ${ }^{16}$ stated: 'interestingly, we found no significant relationship between [vasopressin] dosages or length of infusion and the development of [ischaemic limb lesions]'. Based on higher requirements for plasma and platelet transfusion, the authors speculated that DIC was an important factor in the development of the skin lesions.

Ghosh et $\mathrm{al}^{18}$ reviewed 14 consecutive cases of SPG in a tertiary care hospital in India. Although all their patients had DIC, none were receiving vasoconstrictor therapy at the onset of gangrene. Similarly, Davis et al $^{19}$ found DIC in at least $11 / 12$ patients with SPG referred to dermatology at the Mayo Clinic; only one patient was believed to have developed exacerbation of limb ischaemia in relation to vasopressor therapy.

Interestingly, Hayes and coworkers, evaluating norepinephrine use in four patients who developed SPG in the setting of DIC, noted preserved cardiac function and normal (or even low) calculated systemic vascular resistance, commenting that this 'does not reflect intense vasoconstriction [that is presumably occurring] in the digital vascular bed'. ${ }^{20}$ Similarly paradoxical findings of preserved cardiac index and low systemic vascular resistance despite vasopressor therapy were also observed by Joynt and colleagues. ${ }^{21}$ Although the authors believed that vasopressor therapy must somehow have played an 'important' role in their patient's SPG, they seemed perplexed by why this complication occurred, noting 'we have used adrenaline extensively for septic shock and have not encountered the syndrome previously'.

The Cochrane Collaboration, which in $2016^{22}$ reviewed randomized controlled trials (RCTs) comparing vasopressor regimens on mortality in critically ill patients with shock, found no evidence of substantial mortality differences between six different vasopressors. Although one secondary end point (arrhythmias) occurred more frequently with dopamine (vs. norepinephrine), no other differences in secondary end points were found. In particular, the authors stated that '[o]ther adverse events such as ... skin ischaemias and arterial occlusion did not differ between intervention groups.'22

\section{Timeline of Limb Ischaemic Injury during Vasopressor Therapy}

An important issue is whether vasopressors contribute independently to the pathogenesis of SPG. To address this issue, I performed in June 2017 a PubMed search (using key words 'vasopressor limb gangrene' and 'vasopressor limb ischaemia') to identify in a systematic fashion published cases of SPG. ${ }^{23}$ Review of the individual published cases led to a striking observation: limb ischaemic necrosis did not usually begin soon after initiating vasopressor therapy, but usually after a delay of 2 to 5 days (median, 3 days) after onset of hypotension, and initiation of vasopressor therapy. This suggests a timedependent factor in the pathogenesis of SPG. Moreover, the clinical profiles of the cases were consistent with an underlying DIC state. This is consistent with time-dependent decrease in natural anticoagulants as a key factor explaining this striking temporal profile of SPG. As discussed in the next section, severe 
acute or chronic hepatic dysfunction explains a time-dependent decrease in natural anticoagulants.

\section{Association between Shock Liver and Symmetrical Peripheral Gangrene}

In my experience, at least $90 \%$ of SPG patients have 'shock liver' (also known as 'acute ischaemic hepatitis' and 'hypoxic hepatitis') ${ }^{24}$ preceding the onset of ischaemic limb necrosis by 2 to 5 days (median, 3 days). ${ }^{1}$ Preceding shock liver explains occurrence of SPG by time-dependent decrease to critically low levels of hepatically synthesized natural anticoagulants, PC and AT. Although there is no standard or accepted therapy for treating incipient or established SPG, these novel concepts could help direct future diagnostic and therapeutic approaches.

\section{Initial Case Observation}

In 2012, Deborah Siegal, Richard Cook, and I reported a 61year-old female who developed SPG involving bilateral feet postcardiac arrest. ${ }^{25}$ The patient had acute DIC, shock liver (called 'acute ischaemic hepatitis' and 'acute hepatic necrosis' in our report) with a peak alanine aminotransferase (ALT) level of 2,468 U/L (reference range, $0-28$ ). Notably, there was a 3-day delay between onset of shock liver and beginning of peripheral limb ischaemia. Shortly after onset of limb ischaemia, our patient had extremely low PC activity (1\% of normal) and AT activity (20\% of normal). To test the idea that severe factor deficiency reflected at least in part impaired hepatic synthesis, we measured various procoagulant and anticoagulant factors, performing a regression analysis for 13 different coagulation factors, plotting the various factor levels ( $y$-axis) in relation to their respective half-lives ( $x$-axis). The highly significant correlation $\left(r^{2}=0.62 ; p=0.001\right)$ indicated that short half-life factors (e.g., PC and factor VII) are especially vulnerable to depletion in this clinical setting. Thus, the 3-day interval between shock liver onset and the beginning of critical limb ischaemia (microthrombosis) reflects the time needed for crucial coagulation factors to reach critically low levels in the setting of impaired hepatic synthesis.

\section{Case Series}

Subsequently, I reviewed the clinical and laboratory characteristics of 15 patients who developed SPG in the setting of shock (cardiogenic and septic). ${ }^{26}$ DIC was a consistent feature in all 15 subjects, with unusually low platelet counts (median platelet count nadir, $18 \times 10^{9}$ per litre) and greatly elevated fibrin-specific markers. Markers of shock with associated tissue hypoxia included lactic acidemia (all 15 patients) and normoblastemia (all but one patient). ${ }^{27,28}$ Preceding shock liver was seen in 14/15 (93\%) patients, with a characteristic median delay of 3 days (range, 2-5 days) between onset of shock liver and limb ischaemic necrosis. Two of these 15 cases have been presented in more detail. ${ }^{1,29}$

\section{Impaired Procoagulant-Anticoagulant Balance in Symmetrical Peripheral Gangrene}

Shock liver plays a key pathophysiological role in posing risk for SPG, given the liver's role in synthesizing the two crucial natural anticoagulants, PC and AT. ${ }^{1}$ In my experience, the few SPG patients who do not have preceding shock liver either have chronic liver disease ${ }^{30}$ and/or unusually severe thrombocytopenia (platelet count nadir, $<10 \times 10^{9}$ per litre), along with natural anticoagulant depletion. Severe thrombocytopenia suggests that marked DIC itself could in some cases predispose to severe depletion of natural anticoagulant proteins. In a study of meningococcemia, White and colleagues ${ }^{31}$ found PC and AT activity levels to be the lowest in DIC patients with the highest fibrin D-dimer levels. Further, PC and AT levels-but not protein S levels-were lower in patients who developed meningococcemia-associated purpura fulminans versus patients who did not (protein $S$ is not only made by the liver). Similarly, Powars and colleagues, ${ }^{32}$ who measured coagulation parameters during a meningococcemia epidemic in Los Angeles from 1986 to 1991, noted that 'deforming autoamputation' (proxy for SPG) occurred in 10 patients, with evidence of disturbed procoagulant-anticoagulant balance (platelet count $<50 \times 10^{9}$ per litre, elevated fibrin D-dimers, and PC activity $<50 \%$ ). The literature thus supports a concept of profoundly impaired procoagulant-anticoagulant balance in explaining SPG.

\section{Markers of DIC in SPG}

Severe thrombocytopenia and greatly elevated fibrin-specific markers are commonly observed in SPG. However, other laboratory indicators of DIC-such as prothrombin timeinternational normalized ratio (PT-INR) elevation or hypofibrinogenemia-may not necessarily be prominent in DIC associated with cardiogenic or septic shock. This is in contrast to other types of DIC, such as those occurring after acute trauma or with obstetrical complications, where hypofibrinogenemia is common. ${ }^{33,34}$ Indeed, fibrinogen (acute phase reactant) levels may even be elevated in patients who develop SPG. ${ }^{30}$ Indeed, prodromal infection-prior to onset of bacteremia and septic shock-could worsen risk of SPG by leading to hyperfibrinogenemia, with greater amounts of fibrinogen substrate available for causing microthrombosis when DIC subsequently intensifies. ${ }^{30}$ Given the relevance of recognizing and diagnosing DIC, I discuss scoring systems for DIC later in this article.

\section{Parallels between SPG and Venous Limb Gangrene}

The key pathogenic role of preceding shock liver in predisposing to SPG in acute DIC resembles somewhat the role of warfarin (vitamin $\mathrm{K}$ antagonist) in causing microvascular thrombosis and resulting venous limb gangrene in patients who have deep-vein thrombosis, complicating severe hypercoagulability states such as immune $\mathrm{HIT}^{35}$ or metastatic adenocarcinoma. ${ }^{36}$ Just as warfarin therapy typically precedes the onset of limb ischaemia by 2 to 5 days, shock liver serves as a type of 'warfarin equivalent ${ }^{37}$ in predisposing to severe depletion of natural anticoagulants a few days later. - Table 1 compares and contrasts venous limb gangrene and SPG.

\section{Summary of Two Patients with DIC (One with SPG)}

The complexity of these issues is illustrated in - Fig. 1, which summarizes the clinical and laboratory course of two patients 
Table 1 Comparison between venous limb gangrene and symmetrical peripheral gangrene

\begin{tabular}{|l|l|l|}
\hline Feature & Venous limb gangrene & Symmetric peripheral gangrene \\
\hline Underlying DIC conditions $^{\mathrm{a}}$ & HIT, cancer & Shock (cardiogenic, septic) \\
\hline Concomitant DVT & Yes (in limb with necrosis) & Usually not \\
\hline Natural anticoagulant depletion & PC (vitamin K antagonism in 90\%) & PC, AT (preceding 'shock liver' in $\sim 90 \%$ ) \\
\hline Onset of thrombocytopenia & $\begin{array}{l}\text { Usually, } 5 \text { or more days } \\
\text { after starting heparin }\end{array}$ & Usually, at time of onset of shock \\
\hline Onset of limb ischaemia & $\begin{array}{l}\text { Usually, 2-5 d (median, 3 d) } \\
\text { after starting warfarin }\end{array}$ & $\begin{array}{l}\text { Usually, 2-5 d (median, } 3 \mathrm{~d} \text { ) after onset } \\
\text { of shock liver }\end{array}$ \\
\hline HIT antibodies & Strong positive tests & Negative or weak/moderate positive tests \\
\hline
\end{tabular}

Abbreviations: AT, antithrombin; DIC, disseminated intravascular coagulation; DVT, deep-vein thrombosis; HIT, heparin-induced thrombocytopenia; $P C$, protein $C$.

${ }^{a}$ Only the most common explanations for DIC are listed.

who were in my hospital simultaneously, and in whom I provided haematology consultation.

\section{Cardiogenic Shock Complicated by SPG}

-Fig. 1 A shows the clinical and laboratory picture of a 61-yearold man who was admitted with hypotension secondary to cardiogenic shock associated with biventricular failure (left ventricular ejection fraction $=0.33$ ), severe mitral regurgitation (flail mitral valve), rapid atrial fibrillation, and hepatic congestion. Imaging studies showed diffuse atherosclerosis, including severe stenosis of the inferior mesenteric artery. In addition, he had a 5.9-cm infrarenal abdominal aortic aneurysm with a large amount of mural thrombus. Laboratory studies showed lactic acidemia $(\mathrm{pH}=7.29$; reference range, 7.35-7.45), normoblastemia, and hyperbilirubinemia.

The patient had a laboratory picture of DIC, scoring 8 points (maximum) in the International Society on Thrombosis and Haemostasis (ISTH) scoring system for DIC (2 points for platelet count $<50 \times 10^{9}$ per litre; 2 points for greatly elevated international normalized ratio (INR); 3 points for greatly elevated fibrin D-dimer; 1 point for fibrinogen $<1 \mathrm{~g} / \mathrm{L}$ ). He also had shock liver evident at time of admission, as shown by the peak ALT value of 1,168 U/L, indicating he had likely been hypotensive for some time prior to presentation to hospital.

At the time of my initial assessment, the patient had ischaemic toes, which over the next few hours extended to involve the soles of both feet. Interestingly, this critical period of SPG occurrence coincided with shock (lactic acidemia), DIC, and shock liver, together with severely reduced activity levels of the two natural anticoagulants, PC (nadir, $0.17 \mathrm{U} / \mathrm{mL}$; reference range, $0.70-1.80$ ) and AT (nadir, $0.35 \mathrm{U} /$ $\mathrm{mL}$; reference range, $0.77-1.25)$. Thus, this patient had the clinical picture-shock, DIC, and shock liver-seen in at least $90 \%$ of patients who develop SPG. Despite treatment with intravenous heparin and AT concentrates, progressive dermal changes of ischaemic limb injury were evident.

The patient underwent emergency cardiac surgery (coronary artery bypass $\times 3$, mitral valve repair, and closure of patent foramen ovale), complicated by severe perioperative bleeding, which required numerous blood products, exploratory resternotomy, and eventually recombinant factor VIIa.
Unfortunately, recurrent shock and progressive DIC occurred in the postoperative period, and the patient died on postoperative day 12 . Had he survived, he would have required amputations of both feet.

\section{Cardiogenic Shock Not Complicated by SPG}

-Fig. 1B shows the clinical and laboratory picture of a 69year-old man who underwent elective septal myectomy for severe hypertrophic cardiomyopathy. He did well until postoperative day 2 when he developed cardiogenic shock (hypotension, rapid atrial fibrillation, and lactic academia) with a marked decrease in cardiac output (cardiac index, $<1.5 \mathrm{~L}$ / $\mathrm{min} / \mathrm{m}^{2}$; normal range, $2.5-4$ ) that was refractory to treatment with several vasopressors (norepinephrine, phenylephrine, and vasopressin) and inotropes (dobutamine and milrinone). Although two echocardiograms did not show definitive evidence for tamponade, the cardiac surgeon suspected localized tamponade, and at resternotomy drained $400 \mathrm{~mL}$ of old blood, with immediate and complete correction in cardiac index.

Despite haemodynamic correction, the patient developed progressive DIC, scoring 7 (out of maximum 8) points in the ISTH scoring system for DIC ( 2 points for platelet count $<50 \times 10^{9}$ per litre; 2 points for greatly elevated INR; 3 points for greatly elevated fibrin D-dimer; 0 point for fibrinogen nadir $2.1 \mathrm{~g} / \mathrm{L})$. He also had shock liver, as indicated by the peak ALT value of 3,378 U/L, consistent with severe hypotension documented 12 hours prior to ALT measurement.

Despite having prodromal shock (with shock liver) and subsequent DIC, this patient did not develop peripheral limb ischaemia. Interestingly, the PC and AT nadir values ( 0.20 and $0.40 \mathrm{U} / \mathrm{mL}$, respectively) were not as severely reduced as the other patient. Perhaps more importantly, the patient's shock state improved rapidly after surgical correction of tamponade, as shown by the greatly reduced lactate levels. In my opinion, careful clinical-laboratory correlations of critically ill patients who develop SPG-and of appropriate control subjects who do not-will provide further insights into SPG pathogenesis, much the same as previous detailed studies of patients with HIT- and cancer-associated venous limb gangrene (and suitable controls) led to the surprising discovery 

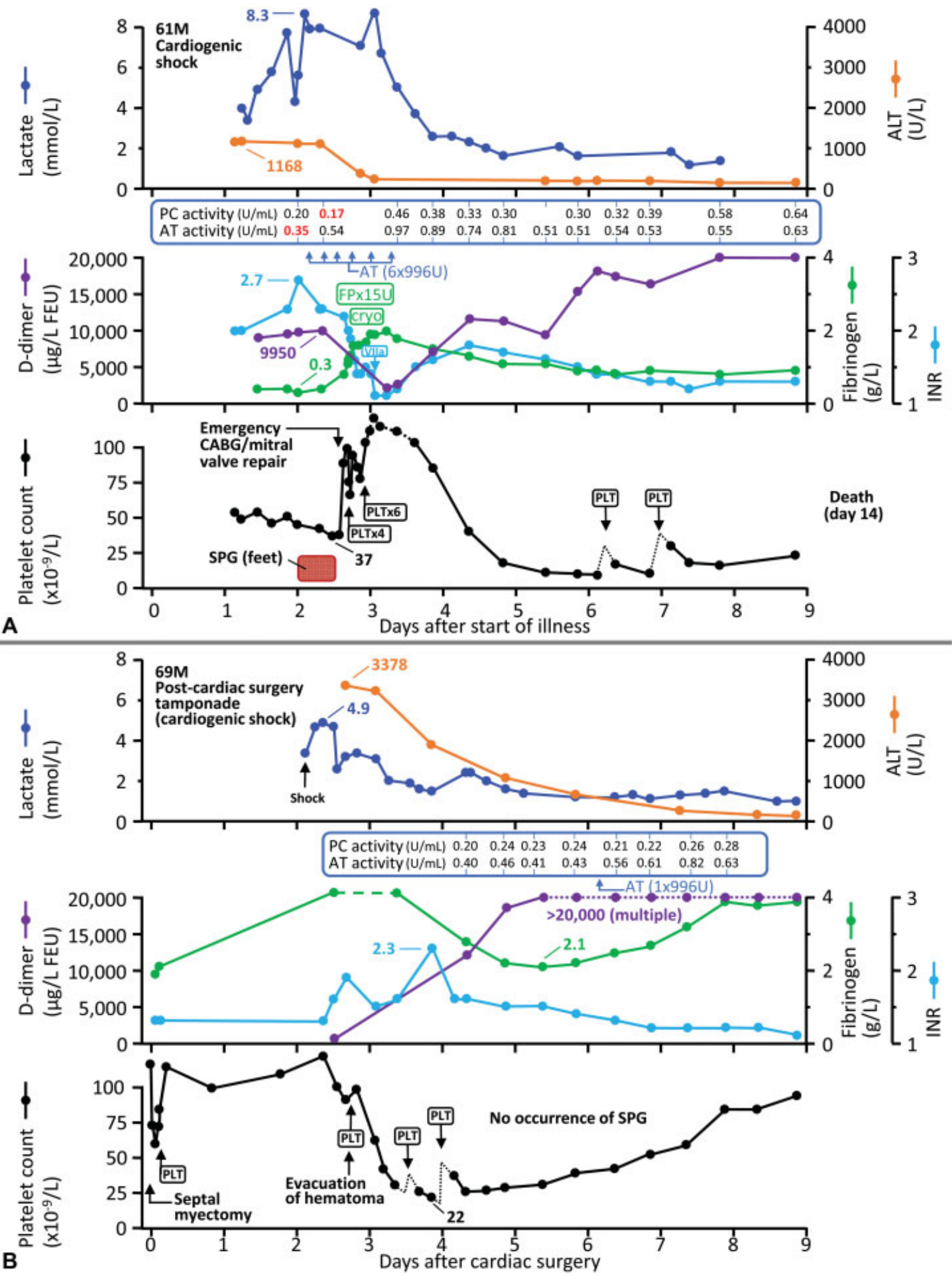

Fig. 1 Two patients with cardiogenic shock, shock liver, and DIC. (A) Patient who developed SPG. At the time of SPG onset, the patient had shock (blood pressure: $86 / 75$, despite norepinephrine, vasopressin, dobutamine, and milrinone; severe lactic acidemia with peak lactate $8.3 \mathrm{mmol} / \mathrm{L}$ ), overt DIC (platelet count: $37 \times 10^{9} / \mathrm{L}$; INR: 2.7; fibrin D-dimer: 9,950 $\mu \mathrm{g} / \mathrm{L}$ of fibrin-equivalent units, and fibrinogen: $0.3 \mathrm{~g} / \mathrm{L}$ ), shock liver (ALT: $1168 \mathrm{U} / \mathrm{L}$ ), and severely reduced levels of PC activity $(0.17 \mathrm{U} / \mathrm{mL}$ ) and AT activity $(0.35 \mathrm{U} / \mathrm{mL})$. (B) Patient who did not develop SPG. Although this patient also had shock (with shock liver), lactic acidemia, overt DIC, and reduced levels of natural anticoagulants, key differences versus the patient depicted in panel $(A)$ included dramatic improvement in lactic acidemia immediately postresternotomy/drainage of pericardial haematoma; thus, the patient's postoperative DIC occurred without concomitant shock, and the AT and PC nadirs were not as severely reduced. ALT, alanine aminotransferase; AT, antithrombin; DIC, disseminated intravascular coagulation; INR, international normalized ratio; PC, protein C; SPG, symmetrical peripheral gangrene. 
of the key pathogenic role of vitamin $\mathrm{K}$ antagonism in explaining progression to ischaemic limb loss. ${ }^{35,36}$

\section{Symmetrical Peripheral Gangrene Research}

Surprisingly little attention has been paid to SPG in the criticalcare literature, both basic and clinical. To my knowledge, animal models of SPG have not been developed; however, an intriguing study of adult mice by Safdar and colleagues ${ }^{38}$ found that silencing of both PC and AT genes (but not when only one gene was silenced) resulted in an acute coagulopathy featuring fibrin deposition and hind-leg necrosis. The authors conclude that there is synergism between the PC and AT anticoagulant systems. This concept is consistent with the role for liver dysfunction in helping to explain SPG occurrence.

Clinical trials of therapeutic interventions in critically ill patients, such as use of AT concentrates, usually evaluate mortality as the primary end point, with secondary end points including parameters such as DIC resolution. To my knowledge, SPG has not been prospectively evaluated as a clinical trial primary-study end point. However, retrospective studies of patients with meningococcemia-associated purpura fulminans have identified severely reduced PC levels, ${ }^{31,39}$ a finding consistent with the role of PC depletion in another disorder characterized by nonacral and acral skin necrosis, namely warfarin-induced skin necrosis. ${ }^{40}$

\section{Scoring Systems for Disseminated Intravascular Coagulation}

Studies of SPG since the 1970s have consistently noted its strong association with DIC; indeed, occurrence of SPG in a critically ill patient with recent or concurrent shock represents a cutaneous manifestation of DIC. To assist clinicians in recognizing DIC, scoring systems for DIC are helpful. The first scoring system was developed 35 years ago under the aegis of the Japanese Ministry of Health and Welfare, and included evaluation of four laboratory criteria (platelet count, prothrombin time, serum-fibrin degradation products, and plasma fibrinogen), ${ }^{41}$ an approach later adopted by the DIC subcommittee of the ISTH. ${ }^{42}$

\section{International Society on Thrombosis and Haemostasis DIC Criteria}

Reflecting the clinical-pathological nature of DIC, the first question asked by the ISTH DIC criteria is a clinical one: does the patient have a disorder known to be associated with DIC? 42 - Table 2 lists various causes of acute DIC. If the answer is 'yes', then four laboratory parameters (discussed subsequently) are evaluated.

The ISTH scoring system evaluates the following four laboratory criteria, with a maximum score of 8 points: thrombocytopenia ( 2 points for platelet count $<50 \times 10^{9}$ per litre; 1 point for platelet count $50-99 \times 10^{9}$ per litre), elevated PT ( 2 points for PT elevated by $>6$ seconds; 1 point for PT elevated by 3-6 seconds), elevated fibrin-specific markers ( 3 points if 'greatly elevated', 2 points if simply 'elevated'), and 1 point if the fibrinogen is reduced to less than $1 \mathrm{~g} / \mathrm{L}$. A score of 5 points or more is consistent with overt DIC. Given that at least 75 to $80 \%$ of patients with DIC have normal fibrinogen levels, ${ }^{43}$ the criterion for hypofibrinogenemia is usually not met. In my experience, ${ }^{26}$ patients with SPG almost always will have a platelet count nadir of $<50 \times 10^{9}$ per litre, and a fibrin-specific marker that is greatly elevated (e.g., D-dimer levels $>10,000 \mu \mathrm{g} / \mathrm{L}$ of fibrinogen-equivalent units), and thus-per the ISTH DIC criteriathese two criteria alone will usually indicate DIC.

\section{Japanese Association for Acute Medicine DIC Criteria}

Several subsequent DIC scoring systems developed in Japan have focused on sepsis-associated DIC. One such scoring system is from the Japanese Association for Acute Medicine (JAAM). ${ }^{44}$ This system initially comprised five criteria (including fibrinogen, with value $<3.5 \mathrm{~g} / \mathrm{L}$ indicating 1 point, and a higher value 0 points), but then the fibrinogen criterion was dropped, so the revised JAAM DIC criteria include systemic inflammatory response syndrome (SIRS) criteria, platelet count (including an assessment of the rapidity of decline), prothrombin time, and fibrin/fibrinogen degradation products (FDPs). ${ }^{44}$ Importantly, significant correlations were found between the maximum DIC score and the

Table 2 Causes of acute DIC

\begin{tabular}{|l|l|}
\hline Causes of acute DIC (selected) & Comment \\
\hline $\begin{array}{l}\text { Shock (cardiogenic, septic, nonseptic } \\
\text { vasodilatory, hypovolemic, etc.) }\end{array}$ & $\begin{array}{l}\text { Most common clinical setting for SPG; elevated lactate levels, acidemia, } \\
\text { and normoblastemia are common laboratory markers of shock }\end{array}$ \\
\hline Infection & $\begin{array}{l}\text { Blood stream invasion (bacteremia, fungemia, and parasitemia) } \\
\text { often associated with DIC }\end{array}$ \\
\hline $\begin{array}{l}\text { Obstetrical complications } \\
\text { placental abruption, retained products, } \\
\text { puerperal sepsis, and amniotic fluid embolism) }\end{array}$ & Hypofibrinogenemia is more common than in many other causes of DIC \\
\hline Cancer & $\begin{array}{l}\text { Metastatic adenocarcinoma is associated with risk of warfarin-associated } \\
\text { venous limb gangrene }\end{array}$ \\
\hline Trauma & Hypofibrinogenemia is an early feature of trauma-associated DIC \\
\hline Heparin-induced thrombocytopenia & Overt DIC is seen in some patients with HIT \\
\hline
\end{tabular}

Abbreviations: DIC, disseminated intravascular coagulation; HIT, heparin-induced thrombocytopenia; SPG, symmetrical peripheral gangrene. Note: Miscellaneous causes of DIC acute include organ necrosis (e.g., necrotizing pancreatitis), envenomation (e.g., snake bite), haemolytic transfusion reaction, and other severe immune-mediated hypersensitivity reactions. 
maximum sequential organ failure assessment (SOFA) score. The JAAM criteria are more sensitive than the ISTH criteria. ${ }^{45}$

\section{Sepsis-Induced Coagulopathy DIC Score}

More recently, and partly in response to revisions in sepsis definition (i.e., 2016 Sepsis-3 definition, which omitted SIRS criteria $){ }^{46}$ a simplified score for 'sepsis-induced coagulopathy' (SIC) was developed. ${ }^{47}$ This system assesses evidence of organ dysfunction (per four SOFA items-respiratory, cardiovascular, hepatic, and renal; 2 points [maximum]) and also evaluates two haemostasis criteria: platelet count $\left(<100 \times 10^{9}\right.$ per litre $=2$ points; $100-149 \times 10^{9}$ per litre $=1$ point $)$ and PTINR ( $>1.4=2$ points; $1.3-1.4=1$ point), with positivity threshold of 4 points or more (maximum score $=6$ points). At least 2 points are needed both for SOFA, as well as 2 points for the haemostasis criteria, to achieve a positive SIC score. Interestingly, the trend to simpler, rapid evaluative criteria is seen both for the clinical criteria (e.g., adoption of a 'quick SOFA' comprising three clinical criteria [alteration in mental status, systolic blood pressure $\leq 100 \mathrm{~mm} \mathrm{Hg}$, and respiratory rate $\geq 22$ per minute] $)^{46}$ and for the laboratory parameters (platelet count and PT-INR). ${ }^{47}$

A comparison of the ISTH scoring system with the SIC system in patients with sepsis showed that the SIC was more sensitive (vs. ISTH criteria) for predicting death, i.e., patients often achieve the SIC scoring threshold prior to meeting the ISTH criteria. ${ }^{48}$ Of note, a SIC score of 6 points (maximum) at baseline (admission) was associated with a mortality rate of approximately $50 \%$. Greater appreciation of DIC in patients with sepsis and/or shock could potentially lead to improved clinical outcomes. ${ }^{49}$

\section{Japanese Society on Thrombosis and Haemostasis DIC Score}

Countering somewhat the trend to simpler scoring systems is the effort to incorporate measurement of AT activity in the evaluation of DIC. In the modified Japanese Society on Thrombosis and Haemostasis DIC scoring system for sepsis-associated DIC, 1 point is given for a percent AT activity level of $<70 \%$ (other parameters used are platelet count, FDP, and PT ratio). ${ }^{50}$ The usefulness of this scoring system would be enhanced if rapid testing for AT levels became widespread, along with the corresponding treatment of DIC with AT concentrates.

\section{Treatments for Disseminated Intravascular Coagulation}

\section{Anticoagulant Therapy}

Anticoagulant therapy, such as with heparin (unfractionated, low molecular weight heparin), is indicated in certain subsets of patients with DIC associated with thrombosis in large veins or arteries. This includes patients with thrombosis complicating adenocarcinoma-associated DIC, in which thrombocytopenia worsens upon stopping heparin, ${ }^{51}$ and where transition to a vitamin $\mathrm{K}$ antagonist can result in venous limb gangrene. ${ }^{36}$ Severe HIT can also be associated with large-vessel thrombosis and DIC, and these patients require anticoagulant treatment.
However, whether to use heparin in patients with sepsis-DIC is unclear: the 2016 Surviving Sepsis guidelines made 'no recommendation' regarding the use of heparin for the treatment of sepsis and septic shock ${ }^{52}$; while acknowledging that there could be a potential survival benefit of heparin, ${ }^{53}$ the "overall impact remains uncertain, and heparin cannot be recommended until further RCTs are performed' ${ }^{52}$

\section{Antithrombin Concentrates as a Treatment for DIC}

Antithrombin concentrates are infrequently used in North America for treating DIC (in contrast, AT concentrates have been approved in Japan since 1987 for the treatment of DIC with reduced AT levels). ${ }^{54}$ Indeed, the 2016 Surviving Sepsis guidelines made a strong recommendation specifically against the use of AT for the treatment of sepsis and septic shock, ${ }^{52}$ citing a meta-analysis by Allingstrup and colleagues, ${ }^{55}$ which found no mortality benefit of AT, but which did suggest increased bleeding risk.

This topic remains controversial, however. One of the failed trials of AT therapy for sepsis, known as KyberSept, ${ }^{56}$ found that in the subgroup of AT-treated patients who had DIC and who did not receive heparin, there was survival benefit. ${ }^{57}$ Umemura and colleagues ${ }^{58}$ performed a meta-analysis of KyberSept and two smaller RCTs, similarly concluding that there was a benefit on mortality: risk ratio $(\mathrm{RR})=0.63(95 \%$ confidence interval $[\mathrm{CI}], 0.45-0.90$ ). The tradeoff with increased bleeding seen in KyberSept remains of concern: RR $=1.71(95 \% \mathrm{Cl}, 1.42-2.06)$, per the analysis of Umemura et al. ${ }^{58}$

In Japan, AT supplementation, ranging between 1,500 and 3,000 U/day, usually administered for 3 consecutive days, to raise AT levels into the normal range ( $>70 \%$ ), is commonly practiced. ${ }^{59}$ This has permitted post-hoc analyses, adjusted for disease severity (propensity scoring), in an attempt to evaluate outcomes of such therapies. For example, Tagami and coworkers, ${ }^{60}$ in an observational nationwide Japanese study of severe pneumonia with sepsis-associated DIC (propensity-matched), suggested that AT administration had a mortality benefit ( 45.7 to $41.1 \%$ ). Yamakawa and colleagues found anticoagulant therapy was associated with survival benefit in patients with sepsis-associated DIC (but different anticoagulant therapies were not analysed separately). ${ }^{61}$

The propensity-matched studies of AT also suggested greater benefit in the subgroup with SOFA scores 13 to 17. ${ }^{61}$ This has led Umemura and Yamakawa ${ }^{62}$ to propose optimal patient selection for anticoagulant therapy, e.g., septic patients with DIC and high organ disease severity.

\section{Thrombomodulin Concentrates as a Treatment for DIC} Recombinant human soluble thrombomodulin (rhsTM, also known as ART-123) has been approved for the treatment of DIC in Japan ${ }^{63}$ on the basis of an RCT showing increased frequency of DIC resolution at 7 days (primary end point) in patients with haematologic malignancy or sepsis; however, there was no difference in mortality ${ }^{64} \mathrm{~A}$ subsequent placebo-controlled, phase 2 study of 741 patients with sepsis and suspected DIC found a trend to a lower 28-day mortality in patients who received rhsTM (17.8 vs. $21.6 \% ; p=0.273$ ), a result that met the predefined threshold indicating possible 
treatment efficacy. ${ }^{65}$ Results of a large phase 3 clinical trial evaluating this novel therapy are expected in July $2019 .^{66}$ Propensity-matched studies for sepsis-associated DIC have found inconsistent but encouraging results with respect to a potential mortality advantage with rhsTM treatment. ${ }^{67-69}$ Although ART-123 has been trialled in the United States, it is neither approved nor available in North America.

Given that thrombomodulin achieves its anticoagulant effects by modifying the substrate specificity of thrombincausing thrombin to convert zymogen PC to activated PC (APC)-it would seem logical to presume that sufficient concentrations of PC would be needed for rhsTM to improve clinical outcomes in patients with DIC. Given the importance of acute liver dysfunction in explaining risk for microvascular thrombosis (by predisposing to reduced levels of PC and AT), it is possible that rhsTM might not decrease SPG risk in patients with shock liver. Indeed, Burlage and coworkers ${ }^{70}$ found that plasma from patients undergoing liver transplantation was resistant to anticoagulant action of ART-123, an effect they attributed to decreased levels of PC and protein S (cofactor for APC) in patients with severe liver disease.

\section{Mortality and SPG: Two Different End Points}

Mortality is typically the primary end point in studies of sepsis. I am unaware of sepsis studies in which SPG is included as a clinical end point (primary or secondary). Indeed, treatments that improve overall sepsis survival may have the unintended side effect of increasing the numbers of patients who survive sepsis at the expense of amputated limbs. This is because the factors that lead to SPG (profound shock, intense DIC, and consequences of shock liver) may not be amenable to meaningful correction. Moreover, the irreversible damage from microvascular thrombosis usually occurs quickly, once the 'perfect storm' circumstances are present.

\section{Pathophysiological Considerations}

SPG can be viewed as the outcome of greatly disturbed procoagulant-anticoagulant balance occurring in at-risk microvasculature. The reality could be even more complex. For example, soluble thrombomodulin levels are elevated in patients with DIC, ${ }^{71,72}$ particularly in the setting of sepsis with organ failure. Endothelial damage or dysfunction could thus additionally contribute to microvascular thrombosis.

\section{Final Comments}

Critical illness is complex and the clinical picture is heterogeneous among patients, with different underlying triggers, host inflammatory response, and number and extent of failing organs. Treatment implications of the new concepts regarding pathogenesis of microvascular thrombosis and limb ischaemic injury remain uncertain. For example, it is a truism that aggressive fluid management is indicated for managing septic shock. ${ }^{73}$ Yet large amounts of crystalloid or colloid administration could exacerbate natural anticoagulant depletion (through haemodilution), with potentially deleterious consequences.
Conflicts of Interest

The author declares the following conflicts of interest: consulting fees from Aspen Global and Octapharma; research support and consulting fees from W.L. Gore and Instrumentation Laboratory; royalties from Informa (Taylor \& Francis); and consulting fees related to medicallegal expert testimony.

\section{References}

1 Warkentin TE. Ischemic limb gangrene with pulses. N Engl J Med 2015;373(07):642-655

2 Perry CB, Davie TB. Symmetrical gangrene in cardiac failure. BMJ 1939;1(4070):15

3 Caserta SJ, Metz R, Anton M. Symmetrical peripheral gangrene in myocardial infarction; report of a case. N Engl J Med 1956;254 (12):568-570

4 Ratnoff OD, Nebehay WG. Multiple coagulative defects in a patient with the Waterhouse-Friderichsen syndrome. Ann Intern Med 1962;56:627-632

5 Rapaport SI, Tatter D, Coeur-Barron N, Hjort PF. Pseudomonas septicemia with intravascular clotting leading to generalized Shwartzman reaction. N Engl J Med 1964;271:80-84

6 Corrigan JJ Jr, Ray WL, May N. Changes in the blood coagulation system associated with septicemia. N Engl J Med 1968;279(16): 851-856

7 Stossel TP, Levy R. Intravascular coagulation associated with pneumococcal bacteremia and symmetrical peripheral gangrene. Arch Intern Med 1970;125(05):876-878

8 Chaudhuri AK, McKenzie P. Peripheral gangrene after measles. BMJ 1970;4(5736):679-680

9 Molos MA, Hall JC. Symmetrical peripheral gangrene and disseminated intravascular coagulation. Arch Dermatol 1985;121 (08):1057-1061

10 Knight TTJr, Gordon SV, Canady J, Rush DS, Browder W. Symmetrical peripheral gangrene: a new presentation of an old disease. Am Surg 2000;66(02):196-199

11 Musher DM. Cutaneous and soft-tissue manifestations of sepsis due to gram-negative enteric bacilli. Rev Infect Dis 1980;2(06): 854-866

12 Robboy SJ, Major MC, Colman RW, Minna JD. Pathology of disseminated intravascular coagulation (DIC). Analysis of 26 cases. Hum Pathol 1972;3(03):327-343

13 Robboy SJ, Mihm MC, Colman RW, Minna JD. The skin in disseminated intravascular coagulation. Prospective analysis of thirty-six cases. Br J Dermatol 1973;88(03):221-229

14 Vincent JL, Nadel S, Kutsogiannis DJ, et al. Drotrecogin alfa (activated) in patients with severe sepsis presenting with purpura fulminans, meningitis, or meningococcal disease: a retrospective analysis of patients enrolled in recent clinical studies. Crit Care 2005;9(04):R331-R343

15 Johansen K, Hansen ST Jr. Symmetrical peripheral gangrene (purpura fulminans) complicating pneumococcal sepsis. Am J Surg 1993;165(05):642-645

16 Dünser MW, Mayr AJ, Tür A, et al. Ischemic skin lesions as a complication of continuous vasopressin infusion in catecholamine-resistant vasodilatory shock: incidence and risk factors. Crit Care Med 2003;31(05):1394-1398

17 RussellJA, Walley KR, Singer J, et al; VASST Investigators. Vasopressin versus norepinephrine infusion in patients with septic shock. N Engl J Med 2008;358(09):877-887

18 Ghosh SK, Bandyopadhyay D, Ghosh A. Symmetrical peripheral gangrene: a prospective study of 14 consecutive cases in a tertiary-care hospital in eastern India. J Eur Acad Dermatol Venereol 2010;24(02):214-218 
19 Davis MD, Dy KM, Nelson S. Presentation and outcome of purpura fulminans associated with peripheral gangrene in 12 patients at Mayo Clinic. J Am Acad Dermatol 2007;57(06):944-956

20 Hayes MA, Yau EHS, Hinds CJ, Watson JD. Symmetrical peripheral gangrene: association with noradrenaline administration. Intensive Care Med 1992;18(07):433-436

21 Joynt G, Doedens L, Lipman J, Bothma P. High-dose adrenaline with low systemic vascular resistance and symmetrical peripheral gangrene. S Afr J Surg 1996;34(02):99-101

22 Gamper G, Havel C, Arrich J, et al. Vasopressors for hypotensive shock. Cochrane Database Syst Rev 2016;2:CD003709

23 Warkentin TE. Symmetrical peripheral gangrene: mechanisms for limb loss in the ICU in patients with retained pulses. Clin Pulm Med 2018;25(02):61-66

24 Waseem N, Chen PH. Hypoxic hepatitis: a review and clinical update. J Clin Transl Hepatol 2016;4(03):263-268

25 Siegal DM, Cook RJ, Warkentin TE. Acute hepatic necrosis and ischemic limb necrosis. N Engl J Med 2012;367(09):879-881

26 Warkentin TE. Heparin-induced thrombocytopenia in critically ill patients. Semin Thromb Hemost 2015;41(01):49-60

27 Constantino BT, Cogionis B. Nucleated RBCs-significance in the peripheral blood film. Lab Med 2000;31(04):223-229

28 Ward HP, Holman J. The association of nucleated red cells in the peripheral smear with hypoxemia. Ann Intern Med 1967;67(06): 1190-1194

29 Warkentin TE. Anticoagulant failure in coagulopathic patients: PTT confounding and other pitfalls. Expert Opin Drug Saf 2014;13 (01):25-43

30 Warkentin TE. Ischemic limb gangrene with pulses. N Engl J Med 2015;373(24):2386-2388

31 White B, Livingstone W, Murphy C, Hodgson A, Rafferty M, Smith OP. An open-label study of the role of adjuvant hemostatic support with protein $\mathrm{C}$ replacement therapy in purpura fulminans-associated meningococcemia. Blood 2000;96(12):3719-3724

32 Powars D, Larsen R, Johnson J, et al. Epidemic meningococcemia and purpura fulminans with induced protein C deficiency. Clin Infect Dis 1993;17(02):254-261

33 Hayakawa M, Gando S, Ono Y, Wada T, Yanagida Y, Sawamura A. Fibrinogen level deteriorates before other routine coagulation parameters and massive transfusion in the early phase of severe trauma: a retrospective observational study. Semin Thromb Hemost 2015;41(01):35-42

34 Parasnis H, Raje B, Hinduja IN. Relevance of plasma fibrinogen estimation in obstetric complications. J Postgrad Med 1992;38 (04):183-185

35 Warkentin TE, Elavathil LJ, Hayward CPM, Johnston MA, Russett JI, Kelton JG. The pathogenesis of venous limb gangrene associated with heparin-induced thrombocytopenia. Ann Intern Med 1997; 127(09):804-812

36 Warkentin TE, Cook RJ, Sarode R, Sloane DA, Crowther MA. Warfarin-induced venous limb ischemia/gangrene complicating cancer: a novel and clinically distinct syndrome. Blood 2015;126 (04):486-493

37 Warkentin TE, Pai M. Shock, acute disseminated intravascular coagulation, and microvascular thrombosis: is 'shock liver' the unrecognized provocateur of ischemic limb necrosis? J Thromb Haemost 2016;14(02):231-235

38 Safdar H, Cheung KL, Salvatori D, et al. Acute and severe coagulopathy in adult mice following silencing of hepatic antithrombin and protein C production. Blood 2013;121(21):4413-4416

39 Fijnvandraat K, Derkx B, Peters M, et al. Coagulation activation and tissue necrosis in meningococcal septic shock: severely reduced protein C levels predict a high mortality. Thromb Haemost 1995; 73(01):15-20

40 Warkentin TE. Coumarin-induced skin necrosis and venous limb gangrene. In: Marder VJ, Aird WC, Bennett JS, Schulman S, White GC, eds. Hemostasis and Thrombosis: Basic Principles and
Clinical Practice, 6th ed. Philadelphia, PA: Lippincott Williams \& Wilkins; 2013:1308-1317

41 Kobayashi N, Maekawa T, Takada M, Tanaka H, Gonmori H. Criteria for diagnosis of DIC based on the analysis of clinical and laboratory findings in 345 DIC patients collected by the Research Committee on DIC in Japan. Bibl Haematol 1983;49 (49):265-275

42 Taylor FB Jr, Toh CH, Hoots WK, Wada H, Levi M; Scientific Subcommittee on Disseminated Intravascular Coagulation (DIC) of the International Society on Thrombosis and Haemostasis (ISTH). Towards definition, clinical and laboratory criteria, and a scoring system for disseminated intravascular coagulation. Thromb Haemost 2001;86(05):1327-1330

43 Takemitsu T, Wada H, Hatada T, et al. Prospective evaluation of three different diagnostic criteria for disseminated intravascular coagulation. Thromb Haemost 2011;105(01):40-44

44 Gando S, Iba T, Eguchi Y, et al; Japanese Association for Acute Medicine Disseminated Intravascular Coagulation (JAAM DIC) Study Group. A multicenter, prospective validation of disseminated intravascular coagulation diagnostic criteria for critically ill patients: comparing current criteria. Crit Care Med 2006;34(03): 625-631

45 Gando S, Saitoh D, Ogura H, et al; Japanese Association for Acute Medicine Disseminated Intravascular Coagulation (JAAM DIC) Study Group. Disseminated intravascular coagulation (DIC) diagnosed based on the Japanese Association for Acute Medicine criteria is a dependent continuum to overt DIC in patients with sepsis. Thromb Res 2009;123(05):715-718

46 Singer M, Deutschman CS, Seymour CW, et al. The Third International Consensus Definitions for Sepsis and Septic Shock (Sepsis-3). JAMA 2016;315(08):801-810

47 Iba T, Nisio MD, Levy JH, Kitamura N, Thachil J. New criteria for sepsis-induced coagulopathy (SIC) following the revised sepsis definition: a retrospective analysis of a nationwide survey. BMJ Open 2017;7(09):e017046

48 Iba T, Arakawa M, Di Nisio M, et al. Newly proposed sepsis-induced coagulopathy precedes International Society on Thrombosis and Haemostasis overt-disseminated intravascular coagulation and predicts high mortality. J Intensive Care Med 2018 (e-pub ahead of print). doi: 10.1177/0885066618773679

49 Umemura Y, Yamakawa K, Hayakawa M, Hamasaki T, Fujimi S; Japan Septic Disseminated Intravascular Coagulation (J-Septic DIC) Study Group. Screening itself for disseminated intravascular coagulation may reduce mortality in sepsis: a nationwide multicenter registry in Japan. Thromb Res 2018;161:60-66

50 Iba T, Di Nisio M, Thachil J, et al. A proposal of the modification of Japanese Society on Thrombosis and Hemostasis (JSTH) disseminated intravascular coagulation (DIC) diagnostic criteria for sepsis-associated DIC. Clin Appl Thromb Hemost 2018;24(03): 439-445

51 Bell WR, Starksen NF, Tong S, Porterfield JK. Trousseau's syndrome. Devastating coagulopathy in the absence of heparin. Am J Med 1985;79(04):423-430

52 Rhodes A, Evans LE, Alhazzani W, et al. Surviving Sepsis Campaign: international guidelines for management of sepsis and septic shock: 2016. Intensive Care Med 2017;43(03):304-377

53 Zarychanski R, Abou-Setta AM, Kanji S, et al; Canadian Critical Care Trials Group. The efficacy and safety of heparin in patients with sepsis: a systematic review and metaanalysis. Crit Care Med 2015;43(03):511-518

54 Iba T, Thachil J. Present and future of anticoagulant therapy using antithrombin and thrombomodulin for sepsis-associated disseminated intravascular coagulation: a perspective from Japan. Int J Hematol 2016;103(03):253-261

55 Allingstrup M, Wetterslev J, Ravn FB, Møller AM, Afshari A. Antithrombin III for critically ill patients. Cochrane Database Syst Rev 2016;2:CD005370 
56 Warren BL, Eid A, Singer P, et al. Caring for the critically ill patient. High-dose antithrombin in severe sepsis: a randomized controlled trial. JAMA 2001;286(15):1869-1878

57 Kienast J, Juers M, Wiedermann CJ, et al; KyberSept investigators. Treatment effects of high-dose antithrombin without concomitant heparin in patients with severe sepsis with or without disseminated intravascular coagulation. J Thromb Haemost 2006;4(01):90-97

58 Umemura Y, Yamakawa K, Ogura H, Yuhara H, Fujimi S. Efficacy and safety of anticoagulant therapy in three specific populations with sepsis: a meta-analysis of randomized controlled trials. J Thromb Haemost 2016;14(03):518-530

59 Hayakawa M, Saito S, Uchino S, et al. Characteristics, treatments, and outcomes of severe sepsis of 3195 ICU-treated adult patients throughout Japan during 2011-2013. J Intensive Care 2016;4:44

60 Tagami T, Matsui H, Horiguchi H, Fushimi K, Yasunaga H. Antithrombin and mortality in severe pneumonia patients with sepsisassociated disseminated intravascular coagulation: an observational nationwide study. J Thromb Haemost 2014;12(09):1470-1479

61 Yamakawa K, Umemura Y, Hayakawa M, et al; Japan Septic Disseminated Intravascular Coagulation (J-Septic DIC) Study Group. Benefit profile of anticoagulant therapy in sepsis: a nationwide multicentre registry in Japan. Crit Care 2016;20(01):229

62 Umemura Y, Yamakawa K. Optimal patient selection for anticoagulant therapy in sepsis: an evidence-based proposal from Japan. J Thromb Haemost 2018;16(03):462-464

63 Ito T, Maruyama I. Thrombomodulin: protectorate God of the vasculature in thrombosis and inflammation. J Thromb Haemost 2011;9(Suppl 1):168-173

64 Saito H, Maruyama I, Shimazaki S, et al. Efficacy and safety of recombinant human soluble thrombomodulin (ART-123) in disseminated intravascular coagulation: results of a phase III, randomized, double-blind clinical trial. J Thromb Haemost 2007;5(01):31-41
65 Vincent JL, Ramesh MK, Ernest D, et al. A randomized, doubleblind, placebo-controlled, Phase $2 \mathrm{~b}$ study to evaluate the safety and efficacy of recombinant human soluble thrombomodulin, ART-123, in patients with sepsis and suspected disseminated intravascular coagulation. Crit Care Med 2013;41(09):2069-2079

66 ClinicalTrails.gov. Available at: http://clinicaltrials.gov/ct2/show/ NCT01598831?term=ART-123\&rank=2. Accessed October 21, 2018

67 Yamakawa K, Ogura H, Fujimi S, et al. Recombinant human soluble thrombomodulin in sepsis-induced disseminated intravascular coagulation: a multicenter propensity score analysis. Intensive Care Med 2013;39(04):644-652

68 Tagami T, Matsui H, Horiguchi H, Fushimi K, Yasunaga H. Recombinant human soluble thrombomodulin and mortality in severe pneumonia patients with sepsis-associated disseminated intravascular coagulation: an observational nationwide study. J Thromb Haemost 2015;13(01):31-40

69 Yoshimura J, Yamakawa K, Ogura H, et al. Benefit profile of recombinant human soluble thrombomodulin in sepsis-induced disseminated intravascular coagulation: a multicenter propensity score analysis. Crit Care 2015;19:78

70 Burlage LC, Bos S, Adelmeijer J, Sakai T, Porte RJ, Lisman T. Plasma from patients undergoing liver transplantation is resistant to anticoagulant activity of soluble thrombomodulin (ART-123). Liver Transpl 2018 (e-pub ahead of print). doi: 10.1002/lt.25318

71 Wada H, Ohiwa M, Kaneko T, et al. Plasma thrombomodulin as a marker of vascular disorders in thrombotic thrombocytopenic purpura and disseminated intravascular coagulation. Am J Hematol 1992;39(01):20-24

72 Iba T, Yagi Y, Kidokoro A, Fukunaga M, Fukunaga T. Increased plasma levels of soluble thrombomodulin in patients with sepsis and organ failure. Surg Today 1995;25(07):585-590

73 Dellinger RP, Schorr CA, Levy MM. A users' guide to the 2016 surviving sepsis guidelines. Intensive Care Med 2017;43(03):299-303 